\title{
Prevalence of K13-propeller gene polymorphisms among Plasmodium falciparum parasites isolated from adult symptomatic patients in northern Uganda
}

\author{
Moses Ocan ${ }^{*}$, Freddie Bwanga ${ }^{2}$, Alfred Okeng $^{3}$, Fred Katabazi ${ }^{2}$, Edgar Kigozi $^{2}$, Samuel Kyobe ${ }^{2}$, \\ Jasper Ogwal-Okeng ${ }^{4}$ and Celestino Obua ${ }^{5}$
}

\begin{abstract}
Background: In the absence of an effective vaccine, malaria treatment and eradication is still a challenge in most endemic areas globally. This is especially the case with the current reported emergence of resistance to artemisinin agents in Southeast Asia. This study therefore explored the prevalence of K13-propeller gene polymorphisms among Plasmodium falciparum parasites in northern Uganda.

Methods: Adult patients ( $\geq 18$ years) presenting to out-patients department of Lira and Gulu regional referral hospitals in northern Uganda were randomly recruited. Laboratory investigation for presence of plasmodium infection among patients was done using Plasmodium falciparum exclusive rapid diagnostic test, histidine rich protein-2 (HRP2) (Pf). Finger prick capillary blood from patients with a positive malaria test was spotted on a filter paper Whatman no. 903. The parasite DNA was extracted using chelex resin method and sequenced for mutations in K13-propeller gene using Sanger sequencing. PCR DNA sequence products were analyzed using in DNAsp 5.10.01 software, data was further processed in Excel spreadsheet 2007.
\end{abstract}

Results: A total of 60 parasite DNA samples were sequenced. Polymorphisms in the K13-propeller gene were detected in four (4) of the 60 parasite DNA samples sequenced. A non-synonymous polymorphism at codon 533 previously detected in Cambodia was found in the parasite DNA samples analyzed. Polymorphisms at codon 522 (non-synonymous) and codon 509 (synonymous) were also found in the samples analyzed. The study found evidence of positive selection in the Plasmodium falciparum population in northern Uganda (Tajima's $D=-1.83205 ; \mathrm{Fu}$ and Li's $D=-1.82458$ ).

Conclusions: Polymorphism in the K13-propeller gene previously reported in Cambodia has been found in the Ugandan Plasmodium falciparum parasites. There is need for continuous surveillance for artemisinin resistance gene markers in the country.

Keywords: Artemisinin, Resistance, Medicines, Northern Uganda

Abbreviations: ACT, Artemisinin combination therapy; ART, Artemisinin therapy; DNA, Deoxyribonucleic acid; dNTP, Deoxyribonucleotide triphosphate; HRP, Histidine rich protein; OPD, Out-Patient Department; PCR, Polymerase chain reaction; $\mathrm{RRH}$, Regional referral hospital; SNP, Single nucleotide polymorphism

\footnotetext{
* Correspondence: ocanmoses@gmail.com

'Department of Pharmacology \& Therapeutics, Makerere University, P. O. Box

7072, Kampala, Uganda

Full list of author information is available at the end of the article
} 


\section{Background}

Malaria is the leading cause of morbidity and mortality in Uganda accounting for 30-50\% of outpatient visits, 15-20\% of hospital admissions and is responsible for nearly half of all inpatient pediatric deaths [1]. Uganda has the third highest number of malaria deaths in Africa in addition to having the highest reported malaria transmission rates in the world [2]. The country also has a high (90-95\%), stable and perennial malaria transmission throughout the year [3]. In Uganda, national policy for treatment of uncomplicated malaria was first changed from chloroquine (CQ) monotherapy to CQ plus sulfadoxine-pyrimethamine (SP) $(\mathrm{CQ}+\mathrm{SP})$ combination therapy in 2000. However this was also changed to the current artemisinin based combination (ACTs) antimalarial agents in 2004 due to wide spread resistance to the earlier agents [4].

The artemisinin agents are rapidly acting and significantly reduce the biomass of sensitive parasites corresponding to a single cycle of a sexual blood stage of Plasmodium falciparum in $48 \mathrm{~h}$ [5]. The use of short acting artemisinin (half-life $<1 \mathrm{~h}$ ) and long-lasting partner drug (lumefantrine, amodiaquine, or piperaquine) in artemisinin-based combination therapy (ACTs), has contributed to an estimated $30 \%$ reduction in global rate of malaria associated mortality in the past decade [6]. However, the emergence of artemisinin resistance in Southeast Asia threatens malaria control and prevention programs globally [7]. With the experience of chloroquine resistance in which it resulted in doubling of malaria associated mortality in sub-Saharan Africa [8], the emergence of artemisinin resistance [9] could potentially pose a similar risk especially in malaria endemic areas of the world.

Artemisinin resistance is currently associated with polymorphisms in the K13-propeller gene [9]. Genomic analysis of Cambodian parasite isolates have identified four prevalent K13-propeller mutations (Y493H, R539T, I543T, and C580Y) that are associated with elevated ring-stage survival rates In vitro and long parasite clearance half-lives ( $>5 \mathrm{~h}$ ) [10]. Evidence from previous studies have indicated that artemisinin resistance affects early ring-stage of the plasmodium parasites' intraerythrocytic developmental cycle [11].

The spread of artemisinin resistance to other parts of the world is quite likely as previous parasite resistance to chloroquine and sulphadoxine-pyrimethamine all arose from the same region, Cambodia and spread globally $[12,13]$. This is further indicated by the current spread of artemisinin resistance in most provinces of Cambodia, Thailand-Myanmar border, southern Vietnam, southern Laos and central Myanmar [14]. It thus seems a matter of time before the K13 gene polymorphisms detected in Cambodia and associated with artemisinin resistance can spread to parts of the world outside Southeast Asia. With limited or no current alternative medicines to artemisinin agents in addition to lack of an effective vaccine, the future of malaria treatment is facing perhaps the greatest test since the emergence of chloroquine resistance more than a decade ago.

With increased use of artemisinin based combination agents in malaria treatment globally [2], surveillance programs are needed to help monitor the emergence and spread of resistance. This study was thus intended to investigate the prevalence of resistance gene markers to artemisinin antimalarial agents among Plasmodium falciparum parasites isolated from adult patients ( $\geq 18$ years) reporting to hospitals in northern Uganda.

\section{Methods}

\section{Study design, area and population}

This was a cross sectional study done among patients presenting with symptoms of malaria (fever) to Lira and Gulu regional referral hospitals (RRHs) in northern Uganda. The two hospitals are more than $300 \mathrm{~km}$ from the capital Kampala and the districts of their location are shown in the map of Uganda, (Fig. 1).

\section{Sampling criteria}

Adult patients ( $\geq 18$ years) reporting to the general laboratory in out-patients department (OPD) with a request from the doctor for a malaria test were all contacted for recruitment into the study using the interval of 4 and 3 in Lira and Gulu regional referral hospitals respectively. Patients who provided written informed consent were then recruited into the study.

\section{Laboratory analysis \\ Sample collection and processing}

Data collection was done from August 2013 to May 2014 with blood sample collection occurring between 8 AM -to- 4 PM on each working day (Monday-to-Friday) during the study period. Capillary blood from a finger prick was collected from each patient after sterilizing the fingertip using alcohol swab. The blood was then tested for presence of plasmodium infection using a Plasmodium falciparum exclusive rapid diagnostic test, HRP2 (Pf) (Access Bio, Inc, USA). The patients with positive result for Plasmodium falciparum infection were notified and more capillary blood collected and spotted on a filter paper Whatman No. 903. Plasmodium parasite DNA was extracted from the dried blood spots on filter paper using chelex resin method as previously described by Plowe, 1995 [15]. Polymorphisms at K13-propeller gene of Plasmodium falciparum parasite was determined using Sanger sequencing. This was done in the molecular diagnostic laboratory (MBN Clinical Laboratories Ltd), P. O. Box 35135, Kampala, Uganda (www.mbnlab.com). 


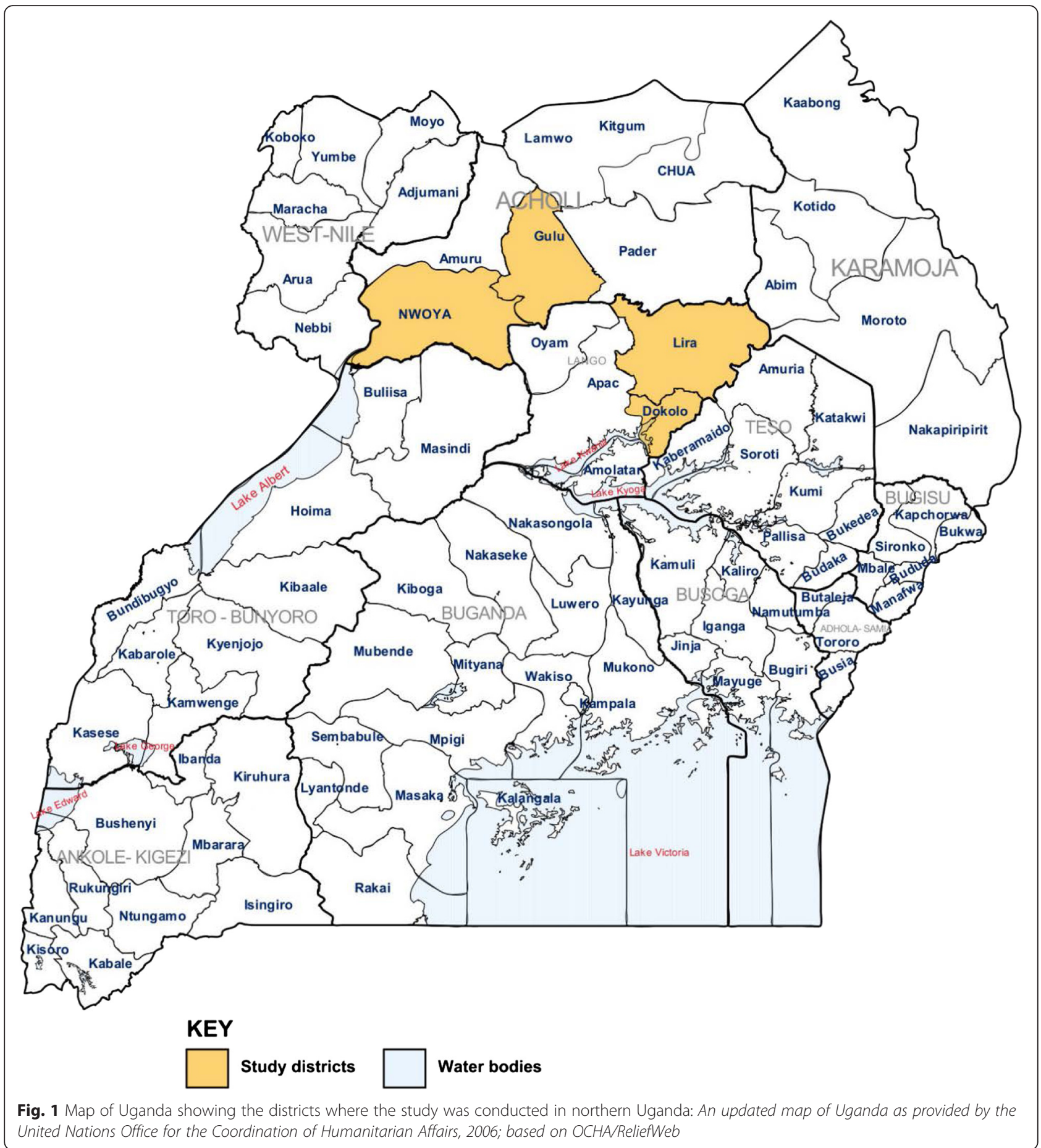

PCR amplification and sequencing of $P$. falciparum isolates For amplification of the K13 gene, we used nested PCR to amplify $849 \mathrm{bp}$ fragment extending from nucleotides 1329-to-2178 (codons 445-to-727) within the entire K13-propeller domain. The first and second round amplification reactions were performed using a Thermal cycler (Bio-Rad, T100; Singapore) in 25 and $50 \mu$ reaction volumes respectively. The K13-propeller domain was amplified using the following primers (Eurofins Genomics, German);

First round PCR (K131-5'CGGAGTGACCAAATCTG GGA-3' and

K134-5' -GGGAATCTGGTGGTAACAGC-3'),

Second round PCR (K133-5'-GCCTTGTTGAAAGA AGCAGA-3';

K132-5'GCCAAGCTGCCATTCATTTG-3'). 
First round PCR was run in a $25 \mu$ reaction volume: briefly, $5.5 \mu \mathrm{l}$ of nuclease free water (QIAGEN, Maryland, USA) was added to $12.5 \mu \mathrm{l}$ of Taq 2X Master Mix (New England BioLabs, Massachusetts, USA). We used Taq 2X Master Mix with the final working concentration of the components at $1 \mathrm{X}$. The concentration of the components at $1 \mathrm{X}$ were: $10 \mathrm{mM}$ Tris- $\mathrm{HCl}, 50 \mathrm{mM} \mathrm{KCl}, 1.5 \mathrm{mM} \mathrm{MgCl}_{2}$, $0.2 \mathrm{mM}$ dNTPs, 25 units/ml Taq DNA Polymerase, $5 \%$ Glycerol, $0.08 \%$ IGEPAL ${ }^{\odot}$ CA-630, $0.05 \%$ Tween $^{\odot}$, $\left.\mathrm{pH} 8.6 @ 25^{\circ} \mathrm{C}\right)$. To this $1.0 \mu \mathrm{l}$ of $10 \mathrm{pmol} / \mu \mathrm{l}$ each of the forward and reverse primers was added. $5.0 \mu \mathrm{l}$ of $50 \mathrm{ng} / \mu \mathrm{l}$ DNA template was then added. The PCR was run using the profile that included Initial denaturation at $94{ }^{\circ} \mathrm{C}$ for $5 \mathrm{~m}$, followed by 40 cycles of Denaturation at $94{ }^{\circ} \mathrm{C}$ for $30 \mathrm{~s}$, Primer annealing at $54{ }^{\circ} \mathrm{C}$ for 90 s and Extension at $68{ }^{\circ} \mathrm{C}$ for 90s. Final extension was then done at $68^{\circ} \mathrm{C}$ for $10 \mathrm{~min}$.

The products of the first round PCR were used as templates for the second round PCR. This was run in a $50 \mu$ reaction volume; briefly, $19 \mu \mathrm{l}$ of nuclease free water (QIAGEN, Maryland, USA) was added to $25 \mu \mathrm{l}$ of Taq 2X Master Mix (New England BioLabs, Massachusetts, USA). The final working concentrations of the components of the Master Mix for the second round PCR were similar to those of the first round PCR. $2.0 \mu \mathrm{l}$ of $10 \mathrm{pmol} / \mu \mathrm{l}$ each of the forward and reverse primers was added. To this mixture was then added $2.0 \mu \mathrm{l}$ of the first round PCR amplicons and the PCR reaction run using the amplification profile as described above.

All PCR products were analyzed using $1 \%(w / v)$ Agarose gel (Fisher Scientific, USA), stained with $0.05 \mu \mathrm{g} / \mathrm{mL}$ of Ethidium Bromide (Sigma Aldrich, USA).

\section{Sequencing of K13 propeller gene}

To sequence the K13 propeller gene, the second round PCR products were purified using jet quick PCR product purification kit (Genomed, Cat number 41-0050). $5 \mu \mathrm{l}$ of the purified second round PCR products were run on $1.0 \%$ (w/v) Agarose gel stained with $0.05 \mu \mathrm{g} / \mathrm{mL}$ of Ethidium Bromide (Sigma Aldrich, USA) to check for the presence and concentration of PCR products. Bi-directional cycle sequencing of K13 was done using second round PCR primers K133 Forward and K132 Reverse (Eurofins Genomics, Germany), using the BigDye terminator v3.1 cycle sequencing kit (Applied Bio systems, USA). The cycle sequencing PCR was performed in a total reaction volume of $20 \mu \mathrm{l}$. Briefly, $6.0 \mu \mathrm{l}$ of the BigDye terminator v3.1 5X sequencing buffer (Applied Bio systems, USA) was aliquoted and mixed with; $2.0 \mu \mathrm{l}$ BigDye terminator v3.1 (Applied Bio systems, USA), 1.0ul of $10 \mathrm{ng} / \mu \mathrm{l}$ (K133Fwd or K132Rev) primers and 6.0ul of nuclease free water. Then, 5.0ul of $5.0 \mathrm{ng} / \mu \mathrm{l}$ of the purified second round PCR products was added. The sequencing reactions where run in the Thermal cycler (Gene Amp 9700 PCR system, USA) under the following conditions. One cycle of Polymerase activation at
$96{ }^{\circ} \mathrm{C}$ for 60 s followed by 35 cycles of; denaturation at $96{ }^{\circ} \mathrm{C}$ for 10 s, annealing at $53{ }^{\circ} \mathrm{C}$ for 30 s, extension at $60{ }^{\circ} \mathrm{C}$ for $300 \mathrm{~s}$. The products were then stored at $4{ }^{\circ} \mathrm{C}$ until the next step. The Extension (Cycle sequencing) PCR products were then purified using DyeEx 2.0 spin Kit (QIAGEN, Maryland, USA). $5.0 \mu \mathrm{l}$ of the purified cycle sequencing PCR products were pipetted and mixed with $5.0 \mu \mathrm{l}$ of De-ionized formamide (Sigma Aldrich, USA). This mixture was then loaded in the 310 genetic analyzer (Applied Bio systems, USA) and the products bi-directional sequenced with POP- $7^{\mathrm{TM}}$ (Applied Bio systems, USA) as a sequencing Polymer.

\section{Sequence data analysis}

The sequence data were base called using the sequence analysis software 5.2 and then blasted on to the NCBI sequence data base to confirm the K13 propeller gene sequences identity. The sequences were imported in to bio edit sequence alignment editor 7.2.5 for manual editing and then exported in to MEGA 5 software version 5.10 for detection of polymorphism using the PF3D7_1343700 K13-propeller gene sequences in NCBI database as the reference sequence. Further SNPs analysis within the K13 propeller gene was performed using the DnaSP software version 5.10.01.

We assessed the selection pressure in Plasmodium falciparum parasite population in northern Uganda using Tajima' D statistic and Fu \& Li's D test in DnaSP software 5.10.01. In this analysis we evaluated whether the $P$. falciparum $\mathrm{K} 13$ propeller domain sequence data shows evidence of deviation from neutrality theory of molecular evolution [16]. A total of 60 (sixty) DNA sample sequence data of $P$. falciparum parasites from Lira and Gulu districts were exported directly from Bioedit into the DnaSP software for computation of Tajima's D and Fu \& Li's D statistic. The analysis was done using commands in the DnaSP software. In DnaSP software, the probability of Tajima's D and Fu \& Li's D are estimated by simulation. The test uses information on frequency of mutations (allelic variation) [17]. Tajima's D and $\mathrm{Fu} \&$ Li's D test is based on the fact that under the neutral model, estimates of the number of polymorphic sites and of the average number of nucleotide differences are correlated. The critical values (Tajima's D and Fu \& Li's D) obtained were used in interpreting the findings under neutrality assumption $[16,18]$.

\section{Tajima's D simulation}

$$
D=\frac{\pi-S / a_{1}}{\sqrt{\operatorname{Var}\left[\pi-S / a_{1}\right]}}
$$

Where, $\pi=$ Mean pairwise differences 
$S=$ Number of segregating sites

$\alpha_{1}=\sum_{i=1}^{n=1} 1 / i$

\section{Fu and Li's D simulation}

$$
D=\frac{S-a_{1 \cap e}}{\sqrt{\operatorname{Var}\left(S-a_{1} \cap e\right)}}
$$

Where,

$\cap e=$ Expected number of derived mutations that are present only once in the sample

$S=$ Number of segregating sites

$a_{1}=\sum_{i=1}^{n=1} 1 / i$

\section{Statistics and analysis}

Data was analyzed in Excel spread sheet 2007.

\section{Results}

We collected blood samples from a total of 100 patients with symptomatic Plasmodium falciparum infection (malaria) who visited out-patient departments of Lira and Gulu regional referral hospitals (50 patients from each hospital). The average age of the study participants was $28 \pm 8.7$. The study was conducted in the outpatient department laboratory of Lira and Gulu regional referral hospitals in northern Uganda. Sixty (60) parasite DNA samples that successfully amplified in the nested PCR reaction for K13-propeller gene were all sequenced.

\section{Prevalence of K13 polymorphisms}

Single nucleotide polymorphisms (SNPs) found in the K13-propeller gene include; 509, 522, and 533 (Table 1 and Additional file 1). One of the nonsynonymous SNPs (533) found in the current study has been previously reported in Cambodia [9]. Mutation at codon 509 was found in two samples while others were present in one sample each.

In total, there were four (4) polymorphic sites identified in the 60 samples analyzed. The mutations in the samples analyzed were not selectively neutral as shown by the negative Tajima's D statistic $(-1.83205)$ and Fu \& Li's D test $(-1.82458)$. There was no significant haplotype/gene diversity $(P=0.215)$ with the variance in diversity of 0.0056 and the standard deviation of 0.075 (Table 2).

\section{Discussion}

Resistance to the artemisinin agents can be assessed using both molecular (genotypic) and phenotypic (Ring Stage survival Assay; $\mathrm{RSA}_{0-3 \mathrm{hr}}$ ) methods. Artemisinin resistance mainly manifests as delayed parasite clearance and is associated with decreased In vitro action of pulses of artemisinin agents $[19,20]$ that is associated with ACT failures [21]. In this study we used molecular parasite characterization to denote existence or absence of resistance to artemisinin agents among the Plasmodium falciparum parasite population in northern Uganda.

In the current study, non-synonymous mutations at codon 522 and 533 of the K13 propeller gene were detected in the Plasmodium falciparum parasites. The mutation at codon 533 found in the current study has previously been reported in Plasmodium falciparum parasites in Cambodia [9]. The parasites carrying this mutation were assessed for phenotypic resistance using RSA ${ }_{0-3 \mathrm{~h}}$ method, and were shown not to be associated with artemisinin resistance in a study by Ariey et al., [22]. A study by Feng et al., [23] reported presence of polymorphism at codons 537 and 574 of the K13 propeller gene in Plasmodium falciparum parasites isolated from Ghanaian migrants to China, mutations previously reported in Cambodia [22]. A mutation at codon 522 found in our study was also reported in a previous study done in Uganda by Conrad et al., [24]. However whether these mutations are associated with Plasmodium falciparum parasite artemisinin resistance has not been demonstrated. Recent studies in Uganda have shown artemisinin agents to be effective in clearing parasites in malaria treatment [25, 26]. A study by Cooper et al., [27] done in Uganda failed to demonstrate in an ex vivo assay using $\mathrm{RSA}_{0-3 \mathrm{hr}}$ method the presence of decreased sensitivity of Plasmodium falciparum parasite isolates to the artemisinin agents.

The polymorphisms in K13-propeller gene, C580Y, R539T, R543I and Y493H reported in Cambodia and associated with artemisinin resistance [9] were not found in the current study. Our findings in addition to those of Feng et al., [23] done in Ghana, and other African countries [28] are indicative of the potential risk of emergence of artemisinin resistance among Plasmodium falciparum parasites in Sub-Saharan Africa. One mutation at codon position 509 found in our study has not previously been reported by other studies. Recent studies

Table 1 Single nucleotide substitutions in K13 gene among the $P$. falciparum samples

\begin{tabular}{|c|c|c|c|c|c|c|c|c|}
\hline $\begin{array}{l}\text { Mutant nucleotide } \\
\text { position }\end{array}$ & $\begin{array}{l}\text { Mutant codon } \\
\text { position }\end{array}$ & $\begin{array}{l}\text { Reference } \\
\text { codon }\end{array}$ & $\begin{array}{l}\text { Mutant } \\
\text { codon }\end{array}$ & Transition & $\begin{array}{l}\text { Reference } \\
\text { amino acid }\end{array}$ & $\begin{array}{l}\text { Mutant } \\
\text { amino acid }\end{array}$ & $\begin{array}{l}\text { Type of } \\
\text { mutation }\end{array}$ & $\begin{array}{l}\text { Prevalence of the } \\
\text { mutation \% (n) }\end{array}$ \\
\hline 1527 & 509 & GAG & GAA & $\mathrm{G} \rightarrow \mathrm{A}$ & Glutamine & Glutamine & $\mathrm{S}$ & $3.3 \%(n=2)$ \\
\hline 1566 & 522 & AGT & $A G G$ & $\mathrm{~T} \rightarrow \mathrm{G}$ & Serine & Arginine & NS & $1.7 \%(n=1)$ \\
\hline 1599 & 533 & GGT & TGT & $\mathrm{G} \rightarrow \mathrm{T}$ & Glycine & Cysteine & NS & $1.7 \%(n=1)$ \\
\hline
\end{tabular}

NS non-synonymous mutation, $S$ synonymous mutation 
Table 2 Haplotype diversity of K13 propeller domain mutation in the DNA analyzed

\begin{tabular}{llll}
\hline K13 analysis parameters & Lira & Gulu & Overall \\
\hline Sample size & 38 & 22 & 60 \\
Number of Haplotypes (h) & 2 & 2 & 4 \\
Haplotype (gene) diversity (Hd) & 0.201 & 0.242 & 0.215 \\
Variance of Haplotype diversity & 0.00728 & 0.01831 & 0.00564 \\
Standard Deviation of Haplotype diversity & 0.085 & 0.135 & 0.075 \\
Number of nucleotide sites analyzed & 587 & 587 & 587 \\
Nucleotide diversity & 0.00287 & 0.00119 & 0.00132 \\
Tajima's D statistic & -0.88600 & -2.27026 & -1.83205 (Not significant; P<0.05) \\
Fu and Li's D test statistic & -0.33513 & -1.9147 & -1.82458 (Not significant; P<0.05) \\
Number of polymorphic sites & 2 & 2 & 4 \\
\hline
\end{tabular}

done in Uganda [24, 27], Africa [28-30], Myanmar [31] have also found mutations in malaria parasites not previously reported in Cambodia [22]. Such geographical variations in the K13-propeller gene mutations is indicative of the existence of a reservoir for the K13-propeller gene polymorphisms globally [28]. However whether this mutations are correlated with reduced parasite clearance in malaria treatment by the artemisinin agents needs to be elucidated as this would help in tracking artemisinin resistance in malaria endemic areas outside of Southeast Asia.

Due to high malaria transmission in sub-Saharan Africa, it is likely that this could result in high use of artemisinin agents. In Uganda, a study by Ocan et al., [32] found high prevalence, $29 \%$ of non-prescription use of ACTs (Coartem) in northern Uganda. Uganda adopted a policy on home based treatment of fever using artemisinin combination agents [33] and presumptive treatment of all fevers as malaria [34]. A report by world health organization [2], also showed a 30-fold increase in the use of ACTs globally between 2006 and 2013. This increased use of artemisinin agents is likely to raise drug pressure and hence the risk of resistance development [35]. In addition, inappropriate use of artemisinin antimalarial agents coupled with the risk of using medicines of substandard quality common in developing countries may further exacerbate the risk of resistance development [2]. Like chloroquine and sulfadoxine-pyrimethamine resistance which first emerged in Southeast Asia then spread to other parts of the world [36], it is possible that the artemisinin resistance that has been detected in Cambodia could also spread through Myanmar via India to Africa [37]. This is likely due to the increased international travel and migration [38]. When we tested the departures of nucleotide variability patterns of the sequence products from neutral expectations using Tajima's D and $\mathrm{Fu} \&$ Li's $\mathrm{D}$ test statistic, there was evidence of positive selection (or selective sweeps) as indicated by the negative values of the tests (Tajima's $\mathrm{D}=-1.83205 ; \mathrm{Fu}$ and Li's D of -1.82458 ) [39]. Previous studies have shown that local ecological and population level processes such as drug pressure are important drivers of resistance development in the population [38-40]. However this study could not establish whether the K13-propeller gene mutations observed in the Plasmodium falciparum parasite population in northern Uganda were as a result of transfer through global human travel or local emergence as a result of ecological and population level processes.

Unlike Africa where Artemisinin agents are mostly used in combinations, studies have shown that up to $78 \%$ of their use in Cambodia are as monotherapy [41]. The basis for artemisinin combination therapy (ACTs) is that the artemisinin component would rapidly reduce parasite load in blood, quickly resolve symptoms, and the partner drug would remain active for days or weeks and 'mop up' any remaining parasites [5]. The use of artemisinin agents in combination coupled with their short half-lives may still be protecting the population from wide spread emergence of resistant parasites [42]. However, Uganda recently also adopted the use of artemisinin monotherapy (IV artesunate) in treatment of complicated malaria [43]. The use of Artemisinin agents especially as monotherapy has been associated with selective pressure in parasites isolated from French Guyana and Senegal [44]. A review by Winzeler, [41] also reported failure of parasite clearance among patients treated with artesunate monotherapy. Therefore use of artemisinin monotherapy could potentially enhance the risk of resistance development in the country.

Artemisinin agents are used in combination and therefore when resistance develops to the artemisinin component the other partner drug could be sufficiently effective in order for the combination to retain its effectiveness. However, studies have also reported existence of resistance to the partner agents commonly used in artemisinin combination therapy; amodiaquine, lumefantrine, and mefloquine $[45,46]$. Therefore development of resistance to the artemisinin component is a potential 
threat to the antimalarial artemisinin combination therapy. Studies in Uganda have not been able to demonstrate failure of parasite clearance by the artemisinin combination agents used in malaria treatment $[24,26]$. However there are reports of decreasing malaria treatment cure rates by the artemisinin combination antimalarial agents in Africa [47] and Asia [48]. Phenotypic and genotypic findings of previous studies [24, 27] coupled with those of our current study in addition to the prevalent inappropriate use of ACTs in communities [49], support the need for regular epidemiological surveillance of resistance to artemisinin agents and the partner drugs currently used in malaria treatment in Uganda.

Currently there is no known alternative medicine to artemisinin based antimalarial agents for malaria treatment globally. Therefore the possibility of emergence of artemisinin resistance is likely to increase the risk of morbidity and mortality from malaria especially in endemic areas of the world. Unfortunately there is no tangible response to the likelihood of artemisinin resistance development in most malaria endemic countries globally. This is indicated by the findings of our current study in which ACTs (Coartem) are easily accessed and used without prescription in the communities [32]. This could further exacerbate the risk of resistance development in the country.

In most parts of the world other than South East Asia, artemisinin combination agents remain very effective antimalarial drugs [50]. In Uganda delayed parasite clearance of ACTs has not yet been detected in malaria treatment [51]. Partial host immunity from repeated exposure due to high malaria transmission common in sub-Saharan Africa may be masking the loss of efficacy to ACTs [52]. A study in Mali showed a correlation between immunity against malaria infection among patient and fast rates of artemisinin-induced parasite clearance [53].

Due to either the low parasite load as we did not quantify parasitaemia during blood sample collection or poor DNA quality, we could not successfully amplify Plasmodium falciparum K13-propeller gene from all the 100 extracted parasite DNA samples.

\section{Conclusion}

This study showed existence of K13-propeller gene mutations among Plasmodium falciparum parasite population in northern Uganda. However the polymorphisms associated with delayed Plasmodium parasite clearance by artemisinin agents previously reported in Cambodia were not found in our study. Regular epidemiological surveillance of molecular and phenotypic artemisinin resistance in the country is thus needed. This will help in tracking the possible development of artemisinin resistance and could help inform updating of malaria treatment guidelines.

\section{Additional file}

Additional file 1: Nucleotide sequences of Plasmodium falciparum DNA samples with mutations. This file contains the nucleotide sequences of the Plasmodium falciparum parasite DNA samples that were found to have polymorphisms and the wild type strains. (PDF $88 \mathrm{~kb}$ )

\section{Acknowledgement}

We would like to thank the administration of the two hospitals for accepting to grant laboratory space for this study and the entire laboratory staff of Lira and Gulu RRHs. We also thank OGAC, NIH and HRSA for the financial support offered through grant number 5R24TW008886.

\section{Funding}

This study was funded by grant number 5R24TW008886 supported by OGAC, NIH and HRSA. This work obtained additional funding from the Swedish Research Council, Grant No. VR2011-7381, and the African Regional Capacity Development for Health Services and Systems Research (ARCADEHSSR), FP7 Grant agreement No. 265970. The funders had no role in study design, data collection and analysis, decision to publish, or preparation of the manuscript.

\section{Availability of data and materials}

All data supporting the findings of this study is contained within the manuscript. In addition, supplementary data is provided in Additional file 1. This file contains nucleotide sequences of the $P$. falciparum parasite DNA samples that were found to have mutations after sequencing.

\section{Authors' contributions}

The authors, MO, CO, JOO and FB conceptualized the study. Field data collection was conducted by $\mathrm{MO}$, and $\mathrm{FB}$. Laboratory analysis was done by SK, EK, FK, AO and MO. The first draft of the manuscript was written by MO. Review of the draft manuscript was done by, CO, JOO, FB, FK, SK, EK and AO. All authors read and approved the final version of the manuscript.

\section{Competing interests}

The authors declare that they have no competing interest.

\section{Consent for publication}

Not applicable.

\section{Ethics approval and consent to participate}

The study was reviewed and approved by the school of medicine ethics and review committee of Makerere University (\# REC REF No. 2012-072). Further approval was sought from the Uganda National Council for Science and Technology (\# HS 126). Permission to conduct the study was also obtained from the administration of the two hospitals. Written informed consent was sought from potential study participants before sample collection. Individual clinical data of the patients was not collected and is not presented in this manuscript

\section{Author details}

${ }^{1}$ Department of Pharmacology \& Therapeutics, Makerere University, P. O. Box 7072, Kampala, Uganda. ${ }^{2}$ Department of Medical Microbiology, Makerere University, P. O. Box 7072, Kampala, Uganda. ${ }^{3}$ MBN Clinical Laboratories, P. O. Box 35135, Kampala, Uganda. ${ }^{4}$ Lira University, P. O. Box 1035, Lira, Uganda. ${ }^{5}$ Mbarara University of Science and Technology, P. O. Box 1410, Mbarara, Uganda.

Received: 18 March 2016 Accepted: 11 August 2016

Published online: 19 August 2016

\section{References}

1. Yeka A, Gasasira A, Mpimbaza A, Achan J, Nankabirwa J, Nsobya S, Staedke SG, Donnelly MJ, Wabwire-Mangen F, Talisuna A, et al. Malaria in Uganda: 
challenges to control on the long road to elimination: I. Epidemiology and current control efforts. Acta Trop. 2012;121(3):184-95.

2. World Health Organization. World malaria report 2013. Geneva: WHO; 2013

3. Okello PE, Van Bortel W, Byaruhanga AM, Correwyn A, Roelants P, Talisuna A, D' Alessandro U, Coosemans M. Variation in malaria transmission intensity in seven sites throughout Uganda. Am J Trop Med Hyg. 2006;75(2):219-25.

4. Nanyunja M, Nabyonga Orem J, Kato F, Kaggwa M, Katureebe C, Saweka J. Malaria treatment policy change and implementation: the case of Uganda. Malar Res Treat. 2011;2011:683167.

5. White NJ. Delaying antimalarial drug resistance with combination therapy. Parasitology. 1999;41:301-8.

6. World Health Organization. Antimicrobial resistance: global report on surveillance. Geneva: WHO; 2014.

7. Dondorp AM, Nosten F, Yi P, Das D, Phyo AP, Tarning J, Lwin KM, Ariey F, Hanpithakpong W, Lee SJ, et al. Artemisinin resistance in Plasmodium falciparum malaria. N Engl J Med. 2009;361:455-67.

8. Korenromp EL, Williams BG, Gouws E, Dye C, Snow RW. Measuring trends in childhood malaria mortality in Africa: a new assessment of progress toward targets based on verbal autopsy. Lancet Infect Dis. 2003;3:349-58.

9. Spring MD, Lin JT, Manning JE, Vanachayangkul P, Somethy S, Bun R, Se Y, Chann S, Ittiverakul M, Siangam P, Kuntawunginn W, Arsanok M, Buathong N, Chaorattanakawee S, Gosi P, Ta-aksorn W, Chanarat N, Sundrakes S, Kong N, Heng TK, Nou S, Teja-isavadharm P, Pichyangkul S, Phann ST, Balasubramanian S, Juliano JJ, Meshnick SR, Chour CM, Prom S, Lanteri CA, Lon C, David L, Saunders DL. Dihydroartemisinin-piperaquine failure associated with a triple mutant including kelch13 C580Y in Cambodia: an observational cohort study. The Lancet Infectious Diseases. 2015;15(6):683-691.

10. Amaratunga C, Witkowski B, Dek D, Try V, Khim N, Miotto O, Ménard D, Fairhursta RM. Plasmodium falciparum Founder Populations in Western Cambodia have reduced artemisinin sensitivity in vitro. Antimicrob Agents Chemother. 2014;58(8):4935-7.

11. Saralamba S, Pan-Ngum W, Maude RJ, Lee SJ, Tarning J, Lindegårdh N, Chotivanich K, Nosten F, Day NP, Socheat D, et al. Intrahost modeling of artemisinin resistance in Plasmodium falciparum. Proc Natl Acad Sci U S A. 2011;108(1):397-402.

12. Roper C, Pearce R, Nair S, Sharp B, Nosten F, Anderson T. Intercontinental spread of pyrimethamine-resistant malaria. Science. 2004;305(5687):1124.

13. Wootton JC, Feng X, Ferdig MT, Cooper RA, Mu J, Baruch DI, Magill AJ, Su XZ Genetic diversity and chloroquine selective sweeps in Plasmodium falciparum. Nature. 2002:418:320-3.

14. Takala-Harrison S, Jacob CG, Arze C, Cummings MP, Silva JC, Dondorp AM, Fukuda MM, Hien TT, Mayxay M, Noedl H, et al. Independent emergence of artemisinin resistance mutations among Plasmodium falciparum in Southeast Asia. J Infect Dis. 2015;211(5):670-9.

15. Plowe CV, Djimde A, Bouare M, Doumbo OK, Wellems TE. Pyrimethamine andproguanil resistance-conferring mutationsin Plasmodium falciparum dihydrofolatereductase: polymerase chain reaction methods for surveillance in Africa. Am J TropMed Hyg. 1995;52:565-8.

16. Tajima F. Statistical method for testing the neutral mutation hypothesis by DNA polymorphism. Genetics. 1989a;123:585-595.

17. Ramírez-Soriano A, Ramos-Onsins SE, Rozas J, Calafell F, Navarro A. Statistical power analysis of neutrality tests under demographic expansions, contractions and bottlenecks with recombination. Genetics. 2008;179(1):555-67.

18. Fu YX, Li WH. Statistical tests of neutrality of mutations. Genetics. 1993;133: 693-709.

19. Straimer J, Gnädig NF, Witkowski B, Amaratunga C, Duru V, Ramadani AP, Dacheux M, Khim N, Zhang L, Lam S, Gregory PD, Urnov FD, MercereauPuijalon O, Benoit-Vical F, Fairhurst RM, Ménard D, Fidock DA. K13-propeller mutations confer artemisinin resistance in Plasmodium falciparum clinical isolates. Science. 2015;347(6220):428-431.

20. Witkowski B. Reduced artemisinin susceptibility of Plasmodium falciparum ring stages in western Cambodia. Antimicrob Agents Chemother. 2013;57:914-23.

21. Lon C, Manning JE, Vanachayangkul P, So M, Sea D, Se Y, Gosi P, Lanteri C, Chaorattanakawee $S$, Sriwichai $S$, et al. Efficacy of two versus three day regimens of dihydroartemisinin-piperaquine for uncomplicated malaria in military personnel in northern Cambodia: an open label randomized trial. PLOS ONE. 2014;9:e93138.

22. Ariey F, Witkowski B, Amaratunga C, Beghain J, Langlois AC, Khim N, Kim S, Duru V, Bouchier C, Ma L, et al. A molecular marker of artemisinin-resistant Plasmodium falciparum malaria. Nature. 2014;505(7481):50-5.
23. Feng J, Li J, Yan H, Feng X, Xia Z. Evaluation of antimalarial resistance marker polymorphism in returned migrant workers in China. Antimicrob Agents Chemother. 2015;59(1):326-30.

24. Conrad MD, Bigira V, Kapisi J, Muhindo M, Kamya MR, Havlir DV, Dorsey G, Rosenthal PJ. Polymorphisms in K13 and falcipain-2 associated with artemisinin resistance are not prevalent in plasmodium falciparum isolated from Ugandan children. PLoS ONE. 2014;9(8):e105690.

25. Arinaitwe E, Wanzira TGSH, Kakuru A, Homsy J, Kalamya J, Kamya MR, Vora N, Greenhouse B, Rosenthal PJ, Tappero J, et al. Artemether-Lumefantrine versus Dihydroartemisinin-Piperaquine for falciparum malaria: a longitudinal, randomized trial in young Ugandan children. Clin Infect Dis. 2009;49(11): 1629-37.

26. Muhindo MK, Kakuru A, Jagannathan P, Talisuna A, Osilo E. Early parasite clearance following artemisinin-based combination therapy among Ugandan children with uncomplicated Plasmodium falciparum malaria. Malar J. 2014;13:32.

27. Cooper RA, Conrad MD, Watson QD, Huezo SJ, Ninsiima H, Tumwebaze P, Nsobya SL, Rosenthal AS. Lack of artemisinin resistance in plasmodium falciparum in Uganda based on parasitological and molecular assays. Antimicrob Agents Chemother. 2015;59(8):5061-4.

28. Taylor SM, Parobek CM, DeConti DK, Kayentao K, Coulibaly SO, Greenwood BM, Tagbor H, Williams J, Bojang K, Njie F, et al. Absence of putative artemisinin resistance mutations among plasmodium falciparum in Sub-Saharan Africa: a molecular epidemiologic study. J Infect Dis. 2015;211:680-8.

29. Huang B, Deng C, Yang T, Xue L, Wang Q, Huang S, Su X-Z, Liu Y, Zheng S, Guan Y, et al. Polymorphisms of the artemisinin resistant marker (K13) in Plasmodium falciparum parasite populations of Grande Comore Island 10 years after artemisinin combination therapy. Parasit Vectors. 2015;8:634.

30. Boussaroque A, Fall B, Madamet M, Camara C, Benoit N, Fall M, Nakoulima A, Dionne P, Fall KB, Diatta B, Diémé Y, Wade B, Pradines B. Emergence of Mutations in the K13 Propeller Gene of Plasmodium falciparum Isolates from Dakar, Senegal, in 2013-2014. Antimicrobial Agents and Chemotherapy. 2016;60(1):624-627.

31. Tun KM, Imwong $M$, Lwin KM, Win AA, Hlaing TM, Hlaing T, Lin K, Kyaw MP, Plewes K, Faiz MA, et al. Spread of artemisinin-resistant Plasmodium falciparum in Myanmar: a cross-sectional survey of the K13 molecular markrer. Lancet Infect Dis. 2015;15:415-21.

32. Ocan M, Bwanga F, Bbosa GS, Bagenda D, Waako P, Ogwal-Okeng J, Obua C. Patterns and predictors of self-medication in Northern Uganda. PLOS ONE. 2014:9(3):e92323.

33. Uganda Ministry of Health. Implementation Guidelines for Home-Based Management of Fever Strategy in Children. 2nd ed. Kampala: MOH; 2005.

34. Uganda Clinical Guidelines. National guidelines for management of common conditions. Kampala: Ministry of Health; 2012.

35. Austin DJ, Kristinnson KG, Anderson RM. The relationship between the volume of antimicrobial consumption in human communities and frequency of resistance. Proc Natl Acad Sci U S A. 1999;96:1152-6.

36. Hastings IM. The origins of antimalarial drug resistance. Trends Parasitol. 2004;20:512-8.

37. White NJ. Artemisinin resistance-the clock is ticking. Lancet. 2010;376:2051-2.

38. Anderson TJ, Roper $\mathrm{C}$. The origins and spread of antimalarial drug resistance: lessons for policy makers. Acta Trop. 2005;94:269-80.

39. Goodall-Copestake WP, Tarling GA, Murphy EJ. On the comparison of population level estimates of haplotype and nucleotide diversity: a case study using the gene Cox 1 in animals. Heredity. 2012;109:50-6.

40. Kryazhimskiy S, Plotkin JB. The population genetics of dN/dS. PLoS Genet. 2008:4:e1000304.

41. Winzeler EA, Manary MJ. Drug resistance genomics of the antimalarial drug artemisinin. Genome Biol. 2014;15:544.

42. Meshnick SR, Taylor TE, Kamchonwongpaisan S. Artemisinin and the antimalarial endoperoxides: from herbal remedy to targeted chemotherapy. Microbiol Rev. 1996;60(2):301-15.

43. Li Q, Weina P. Artesunate: The Best Drug in the Treatment of Severe and Complicated Malaria. Pharmaceuticals (Basel). 2010; 3(7):2322-2332.

44. Jambou R. Resistance of Plasmodium falciparum field isolates to in-vitro artemether and point mutations of the SERCA-type PfATPase6. Lancet. 2005; 366:1960-3

45. Carrara VI, Lwin KM, Phyo AP, Ashley EA, Wiladphaingern J, Sriprawat K, Rijken M, Boel M, McGready R, Proux S, et al. Malaria burden and artemisinin resistance in the mobile and migrant population on the Thai-Myanmar border, 1999-2011: an observational study. PLoS Med. 2013;10:e1001398. 
46. Venkatesan M, Gadalla NB, Stepniewska K, Dahal P, Nsanzabana C, Moriera C, Price RN, Mårtensson A, Rosenthal PJ, Dorsey G, et al. Polymorphisms in plasmodium falciparum chloroquine resistance transporter and multidrug resistance 1 genes: parasite risk factors that affect treatment outcomes for $P$. falciparum malaria after Artemether-Lumefantrine and ArtesunateAmodiaquine. Am J Trop Med Hyg. 2014;91(4):833-43.

47. Ngasala BE, Malmberg M, Carlsson AM, Ferreira PE, Petzold MG, Blessborn D, Bergqvist Y, Gil JP, Premji Z, Björkman A, et al. Efficacy and effectiveness of Artemether-Lumefantrine after initial and repeated treatment in children $<5$ years of age with acute uncomplicated plasmodium falciparum malaria in Rural Tanzania: a randomized trial. Clin Infect Dis. 2011;52(7):873-82.

48. Song J, Socheat D, Tan B, Seila S, Xu Y, Ou F, Sokunthea S, Sophorn L, Zhou C, Deng C, et al. Randomized trials of artemisinin-piperaquine, dihydroartemisinin-piperaquine phosphate and artemether-lumefantrine for the treatment of multi-drug resistant falciparum malaria in CambodiaThailand border area. Malar J. 2011;10:231.

49. Awad A, Eltayeb I, Matowe L, Thalib L. Self-medication with Antibiotics and Antimalarials in the community of Khartoum State, Sudan. J Pharm Pharmaceut Sci. 2005;8(2):326-331.

50. Ashley EA, Dhorda M, Fairhurst RM, Amaratunga C, Lim P, Suon S, Sreng S, Anderson JM, Mao S, Sam B, et al. Spread of artemisinin resistance in plasmodium falciparum malaria. N Engl J Med. 2014:371:411-23.

51. WWARN Parasite Clearance Study Group. Baseline data of parasite clearance in patients with falciparum malaria treated with an artemisinin derivative: an individual patient data meta-analysis. Malaria Journal. 2015;14:359

52. Lopera-Mesa TM, Doumbia S, Chiang S, Zeituni AE, Konate DS, Doumbouya M, Keita AS, Stepniewska K, Traore K, Diakite SA, et al. Plasmodium falciparum clearance rates in response to artesunate in Malian children with malaria: effect of acquired immunity. J Infect Dis. 2013;207:1655-63.

53. Ndour PA, Lopera-Mesa TM, Diakité SAS, Chiang S, Mouri O, Roussel C, Jauréguiberry S, Biligui S, Kendjo E, Claessens A, et al. Plasmodium falciparum clearance is rapid and pitting independent in immune Malian children treated with artesunate for malaria. J Infect Dis. 2015:211(2):290-7.

\section{Submit your next manuscript to BioMed Central and we will help you at every step:}

- We accept pre-submission inquiries

- Our selector tool helps you to find the most relevant journal

- We provide round the clock customer support

- Convenient online submission

- Thorough peer review

- Inclusion in PubMed and all major indexing services

- Maximum visibility for your research

Submit your manuscript at www.biomedcentral.com/submit

) Biomed Central 